\title{
The effect of urinary incontinence status during pregnancy and delivery mode on incontinence postpartum. A cohort study*
}

\author{
SL Wesnes, ${ }^{a}$ S Hunskaar, ${ }^{a}$ K Bo, ${ }^{b}$ G Rortveit ${ }^{a, c}$ \\ ${ }^{a}$ Section for General Practice, Department of Public Health and Primary Health Care, University of Bergen, Bergen, Norway ${ }^{b}$ Department of \\ Sports Medicine, The Norwegian School of Sports Sciences, Oslo, Norway ${ }^{c}$ Research Unit for General Practice, Unifob Health, Bergen, Norway \\ Correspondence: Dr SL Wesnes, Section for General Practice, Department of Public Health and Primary Health Care, University of Bergen, \\ Kalfarveien 31, 5018 Bergen, Norway. Email stian.langeland@isf.uib.no
}

Accepted 13 December 2008. Published Online 11 February 2009.

Objective The objectives of this study were to investigate prevalence of urinary incontinence at 6 months postpartum and to study how continence status during pregnancy and mode of delivery influence urinary incontinence at 6 months postpartum in primiparous women.

Design Cohort study.

Setting Pregnant women attending routine ultrasound examination were recruited to the Norwegian Mother and Child Cohort Study (MoBa).

Population A total of 12679 primigravidas who were continent before pregnancy.

Methods Data are from MoBa, conducted by the Norwegian Institute of Public Health. Data are based on questionnaires answered at week 15 and 30 of pregnancy and 6 months postpartum.

Main outcome measures Urinary incontinence 6 months postpartum is presented as proportions, odds ratios and relative risks (RRs).
Results Urinary incontinence was reported by $31 \%$ of the women 6 months after delivery. Compared with women who were continent during pregnancy, incontinence was more prevalent 6 months after delivery among women who experienced incontinence during pregnancy (adjusted RR 2.3, 95\% CI 2.2-2.4). Adjusted RR for incontinence after spontaneous vaginal delivery compared with elective caesarean section was 3.2 (95\% CI 2.2-4.7) among women who were continent and 2.9 (95\% CI 2.3-3.4) among women who were incontinent in pregnancy.

Conclusion Urinary incontinence was prevalent 6 months postpartum. The association between incontinence postpartum and mode of delivery was not substantially influenced by incontinence status in pregnancy. Prediction of a group with high risk of incontinence according to mode of delivery cannot be based on continence status in pregnancy.

Keywords Caesarean section, cohort study, postpartum, primiparity, urinary incontinence, vaginal birth.

Please cite this paper as: Wesnes S, Hunskaar S, Bo K, Rortveit G. The effect of urinary incontinence status during pregnancy and delivery mode on incontinence postpartum. A cohort study*. BJOG 2009;116:700-707.

\section{Introduction}

Urinary incontinence is a common condition among women. ${ }^{1-4}$ Pregnancy and delivery seem to be major risk factors among young and middle-aged women. ${ }^{4,5}$ However,

\footnotetext{
* Some of the results have been presented as a 3-minute poster presentation at the annual conference of the International Continence Society (ICS) in Rotterdam, 24 August 2007.

Re-use of this article is permitted in accordance with the Creative Commons Deed, Attribution 2.5, which does not permit commercial exploitation.
}

the reported prevalence of urinary incontinence varies widely both during ${ }^{6-8}$ and after pregnancy. ${ }^{9-11}$ Urinary incontinence postpartum is a disorder consisting of incontinence starting before, during and after pregnancy. The group has heterogeneous pathophysiology, and different risk factors may exist depending on the time of origin of the disorder. Urinary incontinence starting before or during pregnancy is likely to be associated with incontinence after pregnancy. Some studies have found it to be an independent risk factor for incontinence postpartum ${ }^{12-14}$ and later in life, ${ }^{15,16}$ but one study found no such association. ${ }^{17}$ The role 
of urinary incontinence during pregnancy, especially incident urinary incontinence, has so far received little attention as a potential risk factor for incontinence after pregnancy and later in life. ${ }^{11,18}$

A series of risk factors seems to be involved in urinary incontinence postpartum and later in life, among which there is growing evidence for the impact of delivery mode. ${ }^{13,19,20}$ Few authors have studied the effect of delivery mode among primiparous women. We could find only one such study that reported analyses stratified for continence status during pregnancy. ${ }^{11}$ Some studies dealing with these issues have methodological weaknesses like poor outcome measures, recall bias and retrospective design. ${ }^{11,21}$ In addition, there are problems with small study groups, small numbers of caesarean sections (CS), missing information on elective and non-elective CS and instrumental vaginal deliveries and no adjustments for important confounders like age and body mass index (BMI). ${ }^{10,12,17,18,22-24}$ We planned the present study to meet some of these challenges.

The Norwegian Mother and Child Cohort Study (MoBa) is a large population-based cohort of pregnant women, with several years of follow up, aiming at investigating health issues among both mothers and children. ${ }^{25}$ The study population in the present substudy consists of primigravid women who were continent before pregnancy, as this is the best available clinical model of a pelvis unexposed to known pregnancyrelated risk factors, ${ }^{26}$ and thereby it is the best population to assess the risk of urinary incontinence associated with pregnancy and delivery. Our objective was first, to investigate the incidence and prevalence of urinary incontinence 6 months after delivery; second, to investigate the impact of continence status in week 30 of pregnancy on urinary incontinence 6 months postpartum and third, to study how mode of delivery may interact with continence status in pregnancy to increase or reduce the risk of urinary incontinence 6 months postpartum.

\section{Materials and methods}

There are approximately 55000 births in Norway annually. The MoBa invited approximately 29000 pregnant women annually from 1999 to participate in the study, aiming at a study population of 100000 women. ${ }^{25} \mathrm{~A}$ total of 39 of about 50 hospitals and maternity units in Norway with more than 100 births annually participate in the study. Two weeks before the routine pregnancy ultrasound examination, an invitation was mailed to the pregnant women. By 2006, 45\% of the invited women had accepted to participate by informed written consent. MoBa is still recruiting in 2008. The women were asked only once. However, given participation, response in follow-up studies was strongly emphasised.

The study obtained data by postal questionnaires at six time points from week 15 in pregnancy to 7 years after birth.
In this study, we used data set from questionnaire 1 (week 15 of pregnancy), questionnaire 3 (week 30 of pregnancy) and questionnaire 4 (6 months postpartum). We included women in their first pregnancy, singletons only, who reported having been continent before pregnancy. Questionnaire 4 was answered by $87 \%$ of the women who answered the questionnaire 3 . Descriptive data based on questionnaires 1 and 3 have been published previously. ${ }^{7}$

We used a symptom-based questionnaire based on the terminology of the International Continence Society (ICS). ${ }^{27}$ The women were asked about current leakage. Incontinence was reported as occurring when coughing/laughing/ sneezing, when running/jumping or if they had leakage accompanied by a strong urge to void. Frequency (never, one to four times per month, one to six times per week, once a day and more than once a day) and amount (droplets and larger volumes) were registered. The two last frequency groups were categorised into 'Once or more a day' for the analyses. We defined a case of urinary incontinence when the woman reported frequency of leakage or amount or both. Women who reported no incontinence but answered the frequency question were regarded incontinent $(n=110)$. Women who failed to answer the incontinence questions postpartum $(n=186)$ and women without information on continence status during pregnancy $(n=16)$ were included in analyses with missing values. We defined severe urinary incontinence as leaking 'Larger amounts' or 'Once or more a day' or both.

Women confirming loss of urine in association with coughing, laughing, sneezing, running or jumping were defined as having a stress incontinence component. Women with urgency accompanying loss of urine were defined as having an urge incontinence component. We use the term 'stress urinary incontinence' for women who had a stress component only, while 'urge urinary incontinence' denotes women who had an urge component only. Women who had symptoms of both components are referred to as having mixed urinary incontinence, according to standardised terminology of lower urinary tract symptoms. ${ }^{27}$

The standard data set from the Medical Birth Registry of Norway was included in the database for the MoBa. The Norwegian Data Inspectorate has approved the linkage of the databases. If the Medical Birth Registry did not have information on previous births, the women were defined as nulliparous and included in this study. The Medical Birth Registry holds information on mode of delivery. CS is categorised as 'elective CS', 'acute CS intended as elective CS', 'acute CS intended as spontaneous vaginal delivery' or 'unspecified CS' in the registry. We use the term 'non-elective CS' to denote the categories of acute CS intended as elective CS, acute CS intended as spontaneous vaginal delivery and unspecified CS as a group. Vaginal delivery is categorised as 'spontaneous vaginal delivery' (SVD), 'forceps delivery' or 
'vacuum delivery'. Continence status during pregnancy and mode of delivery were the exposures in this study.

Age was obtained in week 15 of pregnancy. Based on prevalence curves of urinary incontinence during pregnancy, we categorised age into four age groups $(\leq 26,27-30,31-34$ and $\geq 35$ years). The height was reported at week 15 . We excluded outliers by only including values from $140 \mathrm{~cm}$. BMI was calculated as weight in kilograms/(height in metres $)^{2}$. For BMI, we used the weight reported 6 months postpartum. Outliers for weight were excluded; values from 40-180 kg were included. BMI was categorised into four groups: <20 (underweight), 20-24.9 (normal weight), 25-29.9 (overweight) and $\geq 30 \mathrm{~kg} / \mathrm{m}^{2}$ (obese).

The following potential confounders were explored: age, BMI, sex of baby, head circumference, baby's weight, Apgar score ( 1 and 5 minutes), fetal presentation at delivery (normal occipital, breech, transverse, abnormal fetal head presentation and other), birth time (minutes), prolonged labour, perineal tear grade 3-4 and induction (amniotomy, oxytocin and prostaglandins). The Medical Birth Registry's definitions of the variables are based on the Clinical Guidelines in Obstetrics. $^{28}$ Age and BMI were identified as confounders in this material and are therefore the only variables included in adjusted analyses.

The Norwegian Data Inspectorate approved the MoBa study in 1996 and renewed the approval in 2003. The Regional Ethics Committee for Medical Research, Health Region II, has also endorsed the project.

We defined cumulative incidence of incontinence as any incontinence developed after delivery among women who were continent during pregnancy. Confounding was evaluated and adjusted for by multivariable logistic regression analyses and crosstabs analyses. Effect modification of continence status on the effect of SVD compared with elective CS was tested by use of interaction terms in multivariable logistic regression analyses. We treated independent variables as categorical. Odds ratios were the preliminary outcome measure in our analyses. All odds ratios and odds ratio confidence intervals (CI) were then converted to relative risks (RRs) and corresponding $\mathrm{CI}$ by use of the formula $\mathrm{RR}=\mathrm{OR} /$ $((1-P)+(\mathrm{OR} \times P)) \cdot{ }^{29}$ In this formula, $P$ is the prevalence of urinary incontinence in the unexposed group. Data are presented as mean, odds ratio and RR with 95\% CI. $P$ values less than $5 \%$ were considered statistically significant. SPSS 15.0 for Windows (SPSS Inc., Chicago, IL, USA) was used for statistical analyses.

\section{Results}

A total of 12679 primigravid women were included in this substudy. All women were continent before pregnancy. Mean age was 28 years (range 15-45 years), and mean BMI was $24.1 \mathrm{~kg} / \mathrm{m}^{2}$ (range $14-54 \mathrm{~kg} / \mathrm{m}^{2}$ ). Urinary inconti- nence was reported by 31\% (3991/12 679) of women 6 months after delivery. A total of 14\% (1815/12 679) of the women had delivered by CS. Descriptive data for mode of delivery and continence status during pregnancy are presented in Table 1. Women who delivered by CS had a higher age and BMI than those who delivered vaginally. More women who delivered by CS had babies with diverging fetal presentation and higher head circumference compared with women with vaginal delivery. Women having urinary incontinence during pregnancy had a higher age and BMI compared with those who were continent during pregnancy. Stress incontinence was the most common type of incontinence 6 months postpartum $(n=1728 / 12679 ; 14 \%)$. Only $5 \%(186 / 3991)$ had urinary leakage $\geq 1$ per day and $5 \%$ (212/3991) leaked larger amounts. A total of 43 women had urinary leakage $\geq 1$ per day and simultaneously reported leaking larger amounts. The urinary frequency and amount of leakage were unaltered after delivery among the majority of women (data not shown).

\section{Impact of continence status during pregnancy on postpartum incontinence}

Urinary incontinence 6 months postpartum according to continence status in week 30 of pregnancy is presented in Table 2. A total of 52\% (2605/5026) of the women who were incontinent in pregnancy were continent 6 months postpartum. Urinary incontinence in week 30 of pregnancy was a statistically significant risk factor for persistent urinary incontinence postpartum, with an adjusted RR of 2.3 compared with women who were continent in week 30. A total of $21 \%(1562 / 7561)$ of the women, who were continent before and during pregnancy, had become incontinent 6 months postpartum (cumulative incidence). The strongest associated factors for de novo urinary incontinence in adjusted analysis were forceps delivery (RR 4.0, 95\% CI 2.6-5.8), SVD (RR 3.2, 95\% CI 2.1-4.7), vacuum delivery (RR 3.2, 95\% CI 2.1-4.7), all compared with elective CS. Additionally, age $>35$ years (RR 1.8, 95\% CI 1.5-2.1) and BMI $>30 \mathrm{~kg} / \mathrm{m}^{2}$ (RR 1.8, 95\% CI 1.5-2.1) were significantly associated with de novo incontinence.

\section{Impact of delivery mode}

The prevalence of urinary incontinence 6 months postpartum was in general lower for the CS group (Table 2). There was no statistically significant increased risk associated with any of the three groups of non-elective CS compared with the elective CS group. When these three groups were analysed together, the difference was of borderline significance (RR 1.4, 95\% CI 1.0-1.8). The adjusted RR for urinary incontinence postpartum among women having a SVD was $3.2 \mathrm{com}-$ pared with elective CS. The incidences of urinary incontinence among women who were continent during 
Table 1. Descriptive baseline values of the exposure groups in primigravida women who were continent before pregnancy

\begin{tabular}{|c|c|c|c|c|c|c|c|c|}
\hline & \multicolumn{4}{|c|}{ Mode of delivery } & \multicolumn{4}{|c|}{ Continence status in week 30} \\
\hline & \multicolumn{2}{|c|}{$\begin{array}{l}\text { Caesarean section } \\
\quad(n=1815)\end{array}$} & \multicolumn{2}{|c|}{$\begin{array}{l}\text { Vaginal delivery } \\
(n=10864)\end{array}$} & \multicolumn{2}{|c|}{$\begin{array}{l}\text { Urinary continent during } \\
\text { pregnancy }(n=7561)\end{array}$} & \multicolumn{2}{|c|}{$\begin{array}{l}\text { Urinary incontinent } \\
\text { during pregnancy } \\
\qquad(n=5102)\end{array}$} \\
\hline $\begin{array}{l}\text { Urinary incontinence during } \\
\text { pregnancy }\end{array}$ & 691 & $38 \%$ & 4411 & $41 \%$ & NA & NA & 5102 & $100 \%$ \\
\hline $\begin{array}{l}\text { Urinary continence during } \\
\text { pregnancy }\end{array}$ & 1120 & $62 \%$ & 6441 & $59 \%$ & 7561 & $100 \%$ & NA & NA \\
\hline Age (years)* & 28.9 & 4.3 & 27.9 & 4.5 & 27.9 & 4.2 & 28.2 & 4.4 \\
\hline BMI $\left(\mathrm{kg} / \mathrm{m}^{2}\right)^{*}$ & 25.4 & 4.7 & 23.9 & 4.1 & 23.9 & 4.1 & 24.4 & 4.4 \\
\hline \multicolumn{9}{|l|}{ Characteristic of the neonatals } \\
\hline Gender ( $\%$ boys) & 1001 & $55 \%$ & 5307 & $50 \%$ & 3713 & $49 \%$ & 2588 & $51 \%$ \\
\hline Head circumference $(\mathrm{cm})^{*}$ & 35.4 & 2.1 & 35.1 & 1.7 & 35.2 & 1.8 & 35.1 & 1.6 \\
\hline Weight $(\mathrm{g})^{*}$ & 3500 & 782 & 3532 & 494 & 3528 & 546 & 3525 & 545 \\
\hline Apgar 1 minute* & 8.4 & 1.6 & 8.6 & 1.2 & 8.6 & 1.3 & 8.6 & 1.2 \\
\hline Apgar 5 minutes* & 9.2 & 1.1 & 9.4 & 0.8 & 9.3 & 0.9 & 9.4 & 0.8 \\
\hline \multicolumn{9}{|l|}{ Mode of delivery } \\
\hline Elective CS & 355 & $20 \%$ & NA & NA & 227 & $3 \%$ & 128 & $3 \%$ \\
\hline $\begin{array}{l}\text { Acute CS intended as } \\
\text { elective CS }\end{array}$ & 45 & $3 \%$ & NA & NA & 31 & $0 \%$ & 14 & $0 \%$ \\
\hline $\begin{array}{l}\text { Acute CS intended } \\
\text { as SVD }\end{array}$ & 1348 & $74 \%$ & NA & NA & 824 & 1 & 521 & $10 \%$ \\
\hline Unspecified CS & 67 & $4 \%$ & NA & NA & 38 & $1 \%$ & 28 & $1 \%$ \\
\hline SVD & NA & NA & 8908 & $82 \%$ & 5219 & $69 \%$ & 3677 & $72 \%$ \\
\hline Forceps & NA & NA & 309 & $3 \%$ & 189 & $2 \%$ & 120 & $2 \%$ \\
\hline Vacuum & NA & NA & 1647 & $15 \%$ & 1033 & $14 \%$ & 614 & $12 \%$ \\
\hline \multicolumn{9}{|l|}{ Fetal presentation } \\
\hline Normal occipital & 1160 & $64 \%$ & 9928 & $94 \%$ & 6609 & $90 \%$ & 4466 & $89 \%$ \\
\hline Breech & 414 & $23 \%$ & 204 & $2 \%$ & 354 & $5 \%$ & 263 & $5 \%$ \\
\hline Transverse & 7 & $0 \%$ & 2 & $0 \%$ & 5 & $0 \%$ & 4 & $0 \%$ \\
\hline Abnormal fetal head presentation & 210 & $12 \%$ & 390 & $4 \%$ & 363 & $5 \%$ & 235 & $5 \%$ \\
\hline Other & 23 & $1 \%$ & 57 & $1 \%$ & 50 & $1 \%$ & 30 & $1 \%$ \\
\hline \multicolumn{9}{|l|}{ Duration* } \\
\hline Duration of birth (minutes) & 1258 & 653 & 1206 & 687 & 1203 & 687 & 1231 & 673 \\
\hline \multicolumn{9}{|l|}{ Rupture } \\
\hline Rupture grade $3-4$ & NA & NA & 833 & $8 \%$ & 483 & $6 \%$ & 351 & $7 \%$ \\
\hline \multicolumn{9}{|l|}{ Induction } \\
\hline Amniotomy & 87 & $5 \%$ & 301 & $3 \%$ & 227 & $3 \%$ & 160 & $3 \%$ \\
\hline Oxytocin & 112 & $6 \%$ & 387 & $4 \%$ & 268 & $4 \%$ & 230 & $5 \%$ \\
\hline Prostaglandines & 285 & $16 \%$ & 795 & $7 \%$ & 623 & $8 \%$ & 456 & $9 \%$ \\
\hline \multicolumn{9}{|c|}{ Type of incontinence 6 months postpartum } \\
\hline Stress incontinence & 112 & $6 \%$ & 1616 & $15 \%$ & 651 & $9 \%$ & 1074 & $21 \%$ \\
\hline Urge incontinence & 90 & $5 \%$ & 859 & $8 \%$ & 471 & $6 \%$ & 475 & $9 \%$ \\
\hline Mixed incontinence & 79 & $4 \%$ & 1235 & $11 \%$ & 440 & $6 \%$ & 872 & $17 \%$ \\
\hline \multicolumn{9}{|c|}{ Severity of incontinence 6 months postpartum } \\
\hline Severe urinary incontinence & 27 & $1 \%$ & 331 & $3 \%$ & 118 & $2 \%$ & 239 & $5 \%$ \\
\hline
\end{tabular}

NA, not applicable.

Data are given by two exposure variables: mode of delivery and continence status in week 30 . All data are given as number and proportion unless otherwise stated. Women with missing data were excluded in analyses of continence status in week 30.

*Data are presented as mean and SD. 
Table 2. Prevalence of incontinence 6 months after delivery among women who were continent before pregnancy according to mode of delivery and continence status in week 30

\begin{tabular}{|c|c|c|c|c|c|c|c|}
\hline & \multicolumn{7}{|c|}{ Urinary incontinence 6 months after delivery } \\
\hline & \multirow{2}{*}{$\begin{array}{l}\text { All } \\
N\end{array}$} & \multicolumn{2}{|c|}{ Incontinent women } & \multirow[t]{2}{*}{ Unadjusted OR } & \multirow[t]{2}{*}{ Adjusted OR* } & \multirow[t]{2}{*}{ Adjusted RR* } & \multirow[t]{2}{*}{$95 \% \mathrm{Cl}$} \\
\hline & & $n$ & $\%$ & & & & \\
\hline \multicolumn{8}{|c|}{ Continence status week 30} \\
\hline Continent & 7451 & 1562 & 21 & 1 & 1 & 1 & Reference \\
\hline Incontinent & 5026 & 2421 & 48 & 3.5 & 3.5 & 2.3 & $2.2-2.4$ \\
\hline \multicolumn{8}{|l|}{ Mode of delivery } \\
\hline Elective CS & 354 & 43 & 13 & 1 & 1 & 1 & Reference \\
\hline $\begin{array}{l}\text { Acute CS intended } \\
\text { as elective CS }\end{array}$ & 45 & 7 & 16 & 1.3 & 1.4 & 1.2 & $0.6-3.1$ \\
\hline $\begin{array}{l}\text { Acute CS intended } \\
\text { as SVD }\end{array}$ & 1322 & 220 & 17 & 1.4 & 1.5 & 1.3 & $1.0-2.1$ \\
\hline Unspecified CS & 66 & 11 & 17 & 1.4 & 1.5 & 1.3 & $0.7-3.2$ \\
\hline SVD & 8908 & 3010 & 34 & 3.7 & 4.7 & 3.2 & $2.5-3.9$ \\
\hline Vacuum & 1647 & 587 & 36 & 4.0 & 5.1 & 3.3 & $2.6-4.0$ \\
\hline Forceps & 309 & 113 & 37 & 4.2 & 5.5 & 3.5 & $2.6-4.3$ \\
\hline
\end{tabular}

pregnancy by the different types of delivery are shown in Table 3. After forceps delivery, 30\% became incontinent.

\section{The combined impact of delivery mode and incontinence status during pregnancy}

In the group of women who were continent during pregnancy, $8 \%$ of the women were incontinent after elective CS and $20 \%$ were incontinent after SVD, representing an absolute increase of $12 \%$. The corresponding percentages for women, who were incontinent during pregnancy, were 23 and $51 \%$ with an absolute increase of $28 \%$ (Table 3 ). The percentages were approximately the same when comparing all CS to all vaginal deliveries. In adjusted analysis, the risk of incontinence 6 months after acute CS intended as SVD was statistically significant (RR 1.6) compared with elective CS among women who were incontinent during pregnancy (Table 3). When the three groups of non-elective CS were analysed together, the difference was still significant (RR 1.6, 95\% CI 1.1-2.2). SVD was a strong and statistically significant risk factor for incontinence 6 months after delivery compared with elective CS both among women who were continent in week 30 of pregnancy (RR 3.2) and for women

Table 3. Number $(n)$, percentage and adjusted odds ratio and RR for urinary incontinence 6 months postpartum by delivery mode, stratified for continence status during pregnancy

\begin{tabular}{|c|c|c|c|c|c|c|c|c|c|c|}
\hline & \multicolumn{5}{|c|}{ Continent during pregnancy } & \multicolumn{5}{|c|}{ Incontinent during pregnancy } \\
\hline & $n$ & $\%$ & OR & $\mathbf{R R}$ & $\mathrm{Cl}$ & $n$ & $\%$ & OR & $\mathbf{R R}$ & $\mathrm{Cl}$ \\
\hline Elective CS & 18 & 8 & 1 & 1 & Reference & 25 & 20 & 1 & 1 & Reference \\
\hline $\begin{array}{l}\text { Acute CS intended as elective } \\
\text { CS }\end{array}$ & 4 & 13 & 1.6 & 1.4 & $0.4-4.1$ & 3 & 21 & 1.4 & 1.3 & $0.3-2.9$ \\
\hline Acute CS intended as SVD & 66 & 8 & 1.0 & 1.0 & $0.6-1.7$ & 153 & 30 & 1.9 & 1.6 & $1.1-2.2$ \\
\hline Unspecified CS & 3 & 8 & 0.7 & 0.7 & $0.2-2.8$ & 8 & 29 & 2.0 & 1.7 & $0.7-2.8$ \\
\hline SVD & 1166 & 23 & 3.9 & 3.2 & $2.1-4.7$ & 1837 & 51 & 5.5 & 2.9 & $2.3-3.4$ \\
\hline Vacuum & 250 & 26 & 3.9 & 3.2 & $2.1-4.6$ & 337 & 56 & 6.4 & 3.1 & $2.4-3.6$ \\
\hline Forceps & 55 & 30 & 5.5 & 4.0 & $2.6-5.8$ & 58 & 50 & 4.9 & 2.8 & $2.0-3.4$ \\
\hline
\end{tabular}


incontinent in week 30 (RR 2.9) (Table 3). The difference in RR between these groups was not statistically significant.

\section{Comment}

In this large cohort of primigravid women who were continent before pregnancy, we found considerably raised risks for urinary incontinence postpartum among those who developed urinary incontinence during pregnancy compared with those who were continent. The effect of mode of delivery on urinary incontinence postpartum did not depend on continence status during pregnancy.

We found an odds ratio of 3.5 for urinary incontinence 6 months postpartum among women who were incontinent during pregnancy compared with those who were continent at that time. When reanalysing available data in previously published articles for comparison, odds ratios for urinary incontinence postpartum among primiparous women by continence status during pregnancy vary from 2.5 to $9.2 .^{9,11,12,24,30-33}$ We have identified four studies investigating the relationship between continence status during pregnancy and continence status postpartum in previously continent primigravid women, showing odds ratios of 3.1, ${ }^{12} 4.3,{ }^{11} 5.4^{9}$ and $7.8 .{ }^{33}$ Reasons for the higher odds ratios in three of these articles compared with our study might be higher age of the study population, ${ }^{33}$ restriction to stress urinary incontinence, ${ }^{33}$ investigations 3 months postpartum $^{9,11}$ and the use of interviewers..$^{33}$ Methodological issues like small study populations $\mathrm{s}^{9,33}$ and retrospective design ${ }^{11,12}$ probably contribute to less precision in the results. In addition, there was no possibility for adjustments of odds ratio in our reanalyses. Many authors claim that urinary incontinence during pregnancy is an important predictor for urinary incontinence postpartum and later in life. ${ }^{10,13,15,30,32,34}$ Glazener et al. ${ }^{11}$ was the only group investigating primiparous women who were continent before pregnancy, stratified for continence status during pregnancy and then analysed delivery parameters, similar to our approach. For comparison, we set CS as reference group in Glazener's study and any CS as reference group in our material. Reanalysed this way, the odds ratio for urinary incontinence after vaginal delivery among women who were continent during pregnancy was 3.6 in Glazener's study and 3.3 in ours. Among women who were incontinent during pregnancy, the odds ratios were 2.6 and 2.6, respectively. Although Glazener et al. used a retrospective design with data collection 3 months postpartum, our results correspond very well with theirs.

Incidence of urinary incontinence postpartum among primiparous women who were continent both before and during pregnancy varies from 5 to $20 \% .{ }^{9,11,26}$ We report a cumulative incidence 6 months postpartum of $21 \%$. Reasons for this high incidence may be lower CS rates and higher rates of instrumental vaginal delivery in our study compared with the other studies. ${ }^{9,11,26}$ Also, we have used a low threshold to define urinary incontinence. Our cumulative incidences on urinary incontinence after CS, SVD and instrumental delivery were, however, equal to other studies. ${ }^{26}$ Even though we report high incidence and prevalence of urinary incontinence in this study, only a fraction of the women reported frequent leakage of urine or leaking larger amounts. Other studies have found that most pregnant women are not bothered by their urinary incontinence. $^{35}$

MoBa invited annually 29000 pregnant women in Norway to participate, underscoring that the target population of $\mathrm{MoBa}$ was a population-based and nonselected sample. The response rate among primigravid women was $45 \%$. There may be many reasons for the initial low response rate, ${ }^{36}$ for instance resistance to commitment in a comprehensive study with questionnaires of 16 pages. The study population may thus not be representative for pregnant women in every aspect. There were, however, only minor differences between the MoBa participants and their deliveries compared with all births in Norway in the same period concerning distribution of demographic variables. ${ }^{25}$ There was a socio-economic gradient that influenced prevalence estimates, as women in lower socio-economic classes were underrepresented. ${ }^{25}$ Risk factors such as age and BMI may be distributed differently in lowincome pregnant women. This may have introduced a bias, most probably towards a lower prevalence of incontinence than in the total target population. There is, however, no reason to believe that there was a selection on the basis of incontinence status since the MoBa was a survey covering many topics, and urinary incontinence questions only being a minor issue. We believe that the effect estimates for risk factors investigated in this study were not affected by a significant selection bias. A strength of the MoBa study is that the participating women remained in the study; of women responding on questionnaire in week 30 of pregnancy as many as $87 \%$ completed the questionnaire 6 months postpartum. ${ }^{25}$

To inform clinicians, we present detailed data for nonelective CS by splitting this group into three (those who were intended to deliver vaginally, those who were intended to deliver by elective CS and an unspecified group). There were, however, no significant differences between these groups. When interpreting these data, one has to take into account that the latter two groups contained small numbers of participants. Several studies support our findings in that the birthweight, ${ }^{10,13,30}$ head circumference, ${ }^{9,13}$ sex, ${ }^{11}$ Apgar score, ${ }^{12}$ prolonged labour, ${ }^{9,30}$ induction of labour, ${ }^{32}$ fetal presentation at delivery ${ }^{10-12}$ and perineal tear grade $3-4^{10,13,32}$ are weak or not at all risk factors for urinary incontinence, and these factors did not confound the results in the present study. The Medical Birth Registry obtains information on mode of delivery. We have no information regarding indications for non-elective CS; hence, some confounding by indication may be the case. No further information was obtained on which instrumental delivery failed and resulted in non-elective CS or at what stage of delivery non-elective CS was carried out. This 
kind of missing information is a limitation of this study. The proportion of CS (14.3\%) and forceps $(2.4 \%)$ in this study were quite similar to the proportions for all deliveries in Norway as a whole during this time period (CS 13.5-16.5\% and forceps $1.3-1.9 \%$ ). In adjusted analyses, the association between delivery mode and urinary incontinence postpartum was stronger compared with unadjusted analyses, probably reflecting higher mean BMI and age among women having CS.

We found significant differences in prevalence of urinary incontinence depending on continence status in pregnancy and mode of delivery. However, after adjustment and transferring the estimates to RRs rather than odds ratios, the differences were minor. Odds ratio is a misleading outcome measure in studies with high prevalence in the unexposed group, like in this study. ${ }^{29} \mathrm{We}$ recommend the procedure of transferring odds ratio to $\mathrm{RR}$ for future studies on groups with high prevalence of incontinence. Also, one should be careful to interpret the results into a clinical setting, as this is a study comprising women carefully selected as being primigravid and continent before pregnancy.

We used a symptom-based questionnaire based on definitions of the ICS. ${ }^{27}$ Although the questionnaire was not validated per se, the questions were similar to those of validated instruments. $^{37}$

A major strength in this very large observational cohort is the narrow confidence intervals indicating high precision of the results. The nulliparous continent pelvis represents the best available clinical model of the unexposed pelvis, ${ }^{26}$ and our design is thereby the best to assess the risk of urinary incontinence associated with pregnancy and delivery.

Elective CS was associated with less risk of urinary incontinence postpartum compared with SVD. Women who were continent during pregnancy had statistically significant lower prevalence of urinary incontinence postpartum compared with those who were incontinent. There were, however, no statistically significant differences in risks between women who were continent and incontinent in pregnancy depending on mode of delivery. In conclusion, our findings indicate that the association between mode of delivery and continence status postpartum was not influenced by incontinence status in pregnancy. Prediction of a group with high risk of urinary incontinence according to mode of delivery cannot be based on continence status in pregnancy.

\section{Disclosure of interest}

None.

\section{Contribution to authorship}

S.L.W.: performed analyses and did the main interpretation of data. He wrote the article and approved the final version. G.R.: came up with the research question, helped considerably with the analysis, did the major supervising and revising of the article and have given final approval of the version being published. K.B.: had access to the data set. She has given critical feedback on the article along the way. She has given her final approval of the version being published. S.H.: expressed the objective of the study and the methods to be used, helped with interpretation of the results. He critically revised and commented on drafts of the manuscript. He has given final approval of the version being published.

\section{Details of ethics approval}

The Norwegian Data Inspectorate approved the MoBa study in 1996 and renewed the approval in 2003. The Regional Ethics Committee for Medical Research, Health Region II, Norway, has also endorsed the project. Date of approval: 10 September 1998. Reference number S-95113. Our subanalysis in this project itself does not need its own approval. The Regional Ethics Committee for Medical Research has stated: 'We hereby confirm that the project "Urinary incontinence in women during pregnancy and after delivery. The Norwegian mother and child cohort study" by project supervisor S.L.W., at the Section for General Practice, Department of Public Health and Primary Health Care, University of Bergen, Norway, is exempted from review by the Regional Committee for Medical and Health Research Ethics, Western-Norway'.

\section{Funding}

The article is supported financially by Western Norway Regional Health Authority.

\section{Acknowledgements}

We thank the Mother and Child Cohort Study and the Medical Birth Registry of Norway for access to necessary data. We also thank the Western Norway Regional Health Authority for financial support to S.L.W.

\section{References}

1 Hunskaar S, Lose G, Sykes D, Voss S. The prevalence of urinary incontinence in women in four European countries. BJU Int 2004;93: 324-30.

2 Hannestad YS, Rortveit G, Sandvik H, Hunskaar S. A community-based epidemiological survey of female urinary incontinence: the Norwegian EPINCONT study. J Clin Epidemiol 2000;53:1150-7.

3 Hampel C, Wienhold D, Benken N, Eggersmann C, Thuroff JW. Prevalence and natural history of female incontinence. Eur Urol 1997;32: 3-12.

4 Chiarelli P, Brown WJ. Leaking urine in Australian women: prevalence and associated conditions. Women Health 1999;29:1-13.

5 Rortveit G, Hannestad YS, Daltveit AK, Hunskaar S. Age- and typedependent effects of parity on urinary incontinence: the Norwegian EPINCONT study. Obstet Gynecol 2001;98:1004-10.

6 Hvidman L, Foldspang A, Mommsen S, Bugge Nielsen J. Correlates of urinary incontinence in pregnancy. Int Urogynecol J Pelvic Floor Dysfunct 2002:13:278-83.

7 Wesnes SL, Rortveit G, Bo K, Hunskaar S. Urinary incontinence during pregnancy. Obstet Gynecol 2007;109:922-8.

8 Sampselle CM, DeLancey JOL, Ashton-Miller J. Urinary incontinence in pregnancy and postpartum. Neurourol Urodyn 1996;15:329-30. 
9 Viktrup L, Lose G, Rolff M, Barfoed K. The symptom of stress incontinence caused by pregnancy or delivery in primiparas. Obstet Gynecol 1992;79:945-9.

10 Hvidman L, Foldspang A, Mommsen S, Nielsen JB. Postpartum urinary incontinence. Acta Obstet Gynecol Scand 2003;82:556-63.

11 Glazener CM, Herbison GP, MacArthur C, Lancashire R, McGee MA, Grant AM, et al. New postnatal urinary incontinence: obstetric and other risk factors in primiparae. BJOG 2006;113:208-17.

12 Wilson PD, Herbison RM, Herbison GP. Obstetric practice and the prevalence of urinary incontinence three months after delivery. BJOG 1996; 103:154-61.

13 Burgio KL, Zyczynski H, Locher JL, Richter HE, Redden DT, Wright KC. Urinary incontinence in the 12-month postpartum period. Obstet Gynecol 2003;102:1291-8.

14 Eason E, Labrecque M, Marcoux S, Mondor M. Effects of carrying a pregnancy and of method of delivery on urinary incontinence: a prospective cohort study. BMC Pregnancy Childbirth 2004;4:4.

15 Viktrup L, Rortveit G, Lose G. Risk of stress urinary incontinence twelve years after the first pregnancy and delivery. Obstet Gynecol 2006;108: 248-54.

16 Dolan LM, Hosker GL, Mallett VT, Allen RE, Smith AR. Stress incontinence and pelvic floor neurophysiology 15 years after the first delivery. BJOG 2003;110:1107-14.

17 Meyer S, Schreyer A, De Grandi P, Hohlfeld P. The effects of birth on urinary continence mechanisms and other pelvic-floor characteristics. Obstet Gynecol 1998;92:613-18.

18 Thomason AD, Miller JM, Delancey JO. Urinary incontinence symptoms during and after pregnancy in continent and incontinent primiparas. Int Urogynecol J Pelvic Floor Dysfunct 2007;18:147-51.

19 Rortveit G, Daltveit AK, Hannestad YS, Hunskaar S. Urinary incontinence after vaginal delivery or cesarean section. N Engl J Med 2003; 348:900-7.

20 Kuh D, Cardozo L, Hardy R. Urinary incontinence in middle aged women: childhood enuresis and other lifetime risk factors in a British prospective cohort. J Epidemiol Community Health 1999;53:453-8.

21 Nygaard I. Urinary incontinence: is cesarean delivery protective? Semin Perinatol 2006;30:267-71.

22 Mason L, Glenn S, Walton I, Appleton C. The prevalence of stress incontinence during pregnancy and following delivery. Midwifery 1999;15:120-8.

23 Chaliha C, Khullar V, Stanton SL, Monga A, Sultan AH. Urinary symptoms in pregnancy: are they useful for diagnosis? BJOG 2002;109: $1181-3$.
24 Foldspang A, Hvidman L, Mommsen S, Nielsen JB. Risk of postpartum urinary incontinence associated with pregnancy and mode of delivery. Acta Obstet Gynecol Scand 2004;83:923-7.

25 Magnus P, Irgens LM, Haug K, Nystad W, Skjaerven R, Stoltenberg C. Cohort profile: the Norwegian mother and child cohort study (MoBa). Int J Epidemiol 2006;35:1146-50.

26 Farrell SA, Allen VM, Baskett TF. Parturition and urinary incontinence in primiparas. Obstet Gynecol 2001;97:350-6.

27 Abrams P, Cardozo L, Fall M, Griffiths D, Rosier P, Ulmsten U, et al. The standardisation of terminology of lower urinary tract function: report from the Standardisation Sub-committee of the International Continence Society. Neurourol Urodyn 2002;21:167-78.

28 Dalaker K, Berle E, editors. The Norwegian Society of Obstetrics and Gynecology. Clinical Guidelines in Obstetrics 1999. Oslo, Norway: The Norwegian Medical Association, 1999.

29 Zhang J, Yu KF. What's the relative risk? A method of correcting the odds ratio in cohort studies of common outcomes. JAMA 1998;280: 1690-1.

30 van Brummen $\mathrm{HJ}$, Bruinse HW, van de Pol G, Heintz AP, van der Vaart $\mathrm{CH}$. The effect of vaginal and cesarean delivery on lower urinary tract symptoms: what makes the difference? Int Urogynecol I Pelvic Floor Dysfunct 2007;18:133-9.

31 Fritel X, Fauconnier A, Levet C, Benifla JL. Stress urinary incontinence 4 years after the first delivery: a retrospective cohort survey. Acta Obstet Gynecol Scand 2004;83:941-5.

32 Schytt E, Lindmark G, Waldenstrom U. Symptoms of stress incontinence 1 year after childbirth: prevalence and predictors in a national Swedish sample. Acta Obstet Gynecol Scand 2004;83:928-36.

33 Groutz A, Rimon E, Peled S, Gold R, Pauzner D, Lessing JB, et al. Cesarean section: does it really prevent the development of postpartum stress urinary incontinence? A prospective study of 363 women one year after their first delivery. Neurourol Urodyn 2004;23:2-6.

34 Altman D, Ekstrom A, Gustafsson C, Lopez A, Falconer C, Zetterstrom J. Risk of urinary incontinence after childbirth: a 10-year prospective cohort study. Obstet Gynecol 2006;108:873-8.

35 van Brummen HJ, Bruinse HW, van der Bom JG, Heintz AP, van der Vaart $\mathrm{CH}$. How do the prevalences of urogenital symptoms change during pregnancy? Neurourol Urodyn 2006;25:135-9.

36 Galea S, Tracy M. Participation rates in epidemiologic studies. Ann Epidemiol 2007;17:643-53.

37 Sandvik H, Espuna M, Hunskaar S. Validity of the incontinence severity index: comparison with pad-weighing tests. Int Urogynecol J Pelvic Floor Dysfunct 2006;17:520-4. 